\title{
"O CONCEITO DE RACIONALIDADE EM HABERMAS: A 'GUINADA LINGÜÍSTICA' DA TEORIA CRÍTICA"*
}

\author{
Carlos Eduardo Jordão MACHADO**
}

\begin{abstract}
RESUMO: Este ensaio originalmente foi uma comunicação apresentada na UNICAMP. Foi escrito a propósito da visita de Habermas ao Brasil, esperada para o segundo semestre do ano passado. Seu objetivo imediato era fornecer algumas informaçóes sobre as reflexóes habermasianas mais recentes. Para isto, tentou-se inserir historicamente a proposta habermasiana de uma "razão comunicativa" no atual contexto de generalizada irrupção de formas discursivas fragmentárias relativistas e irracionalistas (o "pós-estruturalismo" francês e o "pensiero debole" italiano são os exemplos estudados). Sem pretender esgotar um tema tão complexo, tentou-se também levantar algumas questóes sobre as possibilidades crítico-cognoscitivas da "guinada lingüística" da filosofia de Habermas e de Apel.
\end{abstract}

UNITERMOS: Razão x irrazão; intransparência; pensamento débil; pós-história; pós-estruturalismo; comunidade da comunicação; agir racional-teleológico x agir comunicativo; crftica da teoria critica.

Como dimensionar as possibilidades de se elaborar uma teoria da racionalidade, no momento em que se assiste à propagação de uma perda generalizada das energias utópicas inerentes aos paradigmas teóricos e práticos da experiência moderna? Esta tem sido a idéia essencial da reflexão habermasiana dos últimos anos. Ela consiste, na verdade, na tentativa de uma reapropriação crítica de fontes teóricas díspares, ao mesmo tempo que busca, através de uma síntese conceitual de monumentalidade e amplitude enciclopédicas, chegar a uma teoria crítica positiva (sistemática) (Nota A). Sabe-se do assombro que proposições de cunho "positivo" e "sistemático", como as de Habermas, provocam em contextos como o nosso nos quais predominam um certo niilismo e uma certa fragmentação dos relatos. Mas isto de certo modo surpreende, levando-se em consideração que a Dialektik der Aufklärung é ponto de partida tanto de Habermas, como referência obrigatória para as críticas do racionalismo e da "razão instrumental". Diante desta inusitada proximidade de referenciais, cabe perguntar se a atual crítica habermasiana à razão "funcional" é ainda compatível com os paradigmas da crítica à razão instrumental oriundos da Dialética do lluminismo. Ou teria a incorporação da "guinada linguística" (linguistic turn) à tradição da filosofia da consciência, operada por Habermas, estabelecido uma ruptura? Com questões como estas queremos apenas esboçar um tema de enquadramento nem sempre nítido: sondar as possibilidades teóricas e práticas de um novo reacoplamento entre razão e emancipação na cultura da modernidade tardia.

\footnotetext{
* Conferência proferida no IFCH da UNICAMP no dia 27/08/1987. Com exceção de algumas notas acrescentadas para esta edição, o texto não sofreu modificaçōes.

** Departamento de História - Instituto de Letras, História e Psicologia - UNESP - 19800 - Assis - SP.
} 
Não é difícil constatar, no atual espírito do tempo, um despotenciamento das energias utópicas. $\mathrm{E}$ isto, cabe reconhecer, é algo mais do que um mero sinal de pessimismo cultural transitório ou indício de uma debilitação passageira daquele amálgama que uniu - na experiência moderna da consciência do tempo, desde as jornadas da Revolução Francesa até o "tempo inflacionado" (Bloch) da revolução dos sovietes em 1917 - pensamento histórico e pensamento utópico.

Observa-se, ao mesmo tempo, um deslocamento das expectativas utópicas. Outrora elas tinham a função de vislumbrar espaços de possibilidades orientados para um mais-além-concreto, para aquilo que Ernst Bloch denominou de um "ainda-não-ser" (Noch-Nicht-Sein) concreto. Agora elas se deslocam para a esfera da religião. Este é justamente um movimento inverso ao daquele que ocorreu no final do século XVIII, quando pensamento utópico e pensamento histórico fundiram-se, configurando o espaço público político dos povos modernos e o horizonte de possibilidades de produção de novos paradigmas. A dimensão de futuro portanto se apresenta hoje carregada negativamente, imersa naquela atmosfera que Habermas denomina de "nova intransparência" (9).

Nos últimos dez anos, a recepção e a revalorização das obras de Benjamin, de Bloch, do jovem Lukács e, mais recentemente, de Franz Rosenzweig têm sido, eṃ boa medida, uma manifestação deste discurso intransparente que desvia a utopia para a esfera da religião. A trajetória de Massimo Cacciari é, neste sentido, altamente representativa. Vale lembrar que seu último livro é um trabalho sobre Rosenzweig. Nele esta reapropriação teológica da utopia talvez seja não mais do que expressão de angústia de toda criatura que vê na morte "todo o conhecer do todo" (Rosenzweig). Talvez também por isso Cacciari não se coloque nem ao lado dos "nostálgicos do carisma político de massas" nem ao lado dos "sacerdotes da 'superação' contínua", mas ao contrário, ao lado daqueles movimentos que anteriormente surpreendiam. Sua leitura, no entanto, dificilmente escapa de uma certa atmosfera de "narcisismo-lingüístico-literário" (Nota B). Se é difícil encontrar na interpretação de Cacciari uma base real para problematizar o sentido daqueles movimentos, isto se deve também ao fato dele ser em relação a estes movimentos um mero "Nachbücher" (Nota C).

Seus trabalhos mais conhecidos da década de setenta sobre a idéia de "crise" e sobre o "pensamento negativo" e, principalmente, sua produção mais recente sobre a Viena do início do século - em que os desenhos "surpreendentes" de Kubin não são ofuscados pela pintura de ornamentalismo quase delituoso de um Klimt (6) -, o trabalho sobre o ícone - em que redescobre Pavel Florensky como um dos precursores teóricos do suprematismo russo, que com Mallevitch alcança a sua expressão plástico-visual mais concreta (7) - assim como seu último livro L'Angello della Stella formam, em seu conjunto, um exemplo desta tendência migratória do pensamento utópico para a esfera da religião.

A perda da dimensão utópica do pensamento histórico faz com que este, mais voltado para a realidade tal qual ela é e não como deveria ser, sofra uma debilitação de sua capacidade volitiva. Ao se articular tentacularmente com mecanismos anônimos de poder e ao ser panopticamente controlado por estratégias orientadas monologicamente pela "razão instrumental", o pensamento histórico oblitera as condições de se poder pensar o futuro. $\mathrm{O}$ abandono da utopia por parte do pensamento histórico faz com que a dimensão de futuro, do que ainda-não-é, mas que pode vir a ser, se desvincule do sensivel e, conseqüentemente, debilite a possibilidade de o sujeito, cada vez mais descentrado, se potenciar. 
Segundo Gianni Vattimo e Pier Aldo Rovatti, nas discussões filosóficas da década de sessenta pretendia-se chegar a uma refundição das disciplinas, em particular das ciências humanas, que configurasse uma trama ou estruturalista ou fenomenológica. Visava-se com isto encontrar um campo de subjetividade mais fluido, "não substancialista". O exemplo mais palpável deste esforço era dado pelas discussões em torno dos fundamentos do marxismo. Na década de setenta, como reação ao estruturalismo e às teorias da nova subjetividade, entrou em cena um pensamento sem redenção, "negativo". A própria noção de verdade entrou em crise. $\mathrm{Na}$ França, Foucault tentava ultrapassar os limites do estruturalismo através de uma multiplicidade de estratégias regionais, de dispositivos locais, horizontais, sem se perguntar sobre qual sujeito ou para qual finalidade. O próprio sujeito e o próprio "sentido" da história eram considerados como produtos secundários e enganosos. Na Itália, o debate em torno da "crise da razão" tentou "salvá-la" da "fantasmagoria irracionalista". Nietzsche, Benjamin, Heidegger e o próprio Wittgenstein passaram para o primeiro plano: produziu-se toda uma série de "pastiches sintomáticos", que não eram mais que uma resistência à idéia de teoria entendida como "poder", "controle", "totalização" (19). Segundo Vattimo e Rovatti, a noção de "pensamento débil" se referia, antes de tudo, ao fato de que se deveria levar em consideração a descoberta nietzscheana, presente também no marxismo, do nexo entre "evidência metafísica" e "relações de domínio", dentro e fora do sujeito. Este procedimento não traria como implicação imediata uma filosofia da emancipação que visasse ao desmascaramento e à desmistificação. Ao contrário: dever-se-ia voltar a atenção para a aparência, para a apreensão dos procedimentos discursivos como possibilidade de "novas experiências do ser". Esta possibilidade não seria idêntica ao sentido da "glorificação" dos 'simulacros, como em Deleuze, mas antes ao sentido da Lichtung heideggeriana. Para um tal programa dever-se-ia retomar a "identidade entre o ser e a linguagem". A "debilidade" é apenas um aspecto do impasse que o pensamento encontra nas suas relações com o mundo depois da aventura metafísica. A racionalização deve "despotenciar-se". O pensamento não pode permanecer paralisado em função da ausência de perspectivas estáveis, cartesianas. Nesse sentido, "o pensamento débil" é uma metáfora, um paradoxo, um modo de dizer sobre o provisório, que se inicia com uma perda, uma renúncia.

Vattimo toma a crítica heideggeriana do humanismo e a postura nietzcheana do "niilismo completo" como momentos "positivos" para uma reconstrução filosófica da pós-modernidade e não apenas como sintomas de "decadência". Enquanto críticos das idéias de fundamento e origem, Nietzsche e Heidegger podem ser considerados coṇ̂ filósofos da pós-modernidade. Para se determinar a pós-modernidade na história, deve-se constatar que um dos conteúdos das filosofias dos séculos XIX e XX está na negação das estruturas estáveis do ser, na dissolução das idéias de "história", "progresso" e "superação". O pós-moderno se caracteriza pela decomposição, banalização e declínio da categoria do "novo", como experiência do "fim da história" (20). A experiência do fim da história aparece largamente difundida na cultura deste século. A possibilidade de uma catástrofe atômica apenas intensificou este sentimento. Sentimento que não é imotivado: as técnicas e os sistemas de informação promoveram uma espécie de imobilização da noção de história. O mundo dos mídia é o mundo em que os centros da história se multiplicaram, pois com ele tornou-se possível a construção e a transmissão de uma imagem global das vivências humanas. A história contemporânea é a história em que, através dos meios de comunicação, tudo é nivelado ao plano da sincronia e da simultaneidade, produzindo uma generalizada "des-historicização" da experiência. Para Vattimo, fomos lançados na "pós-história" (Nota D; 20, p. 12). 
Poderemos analisar mais detalhadamente as propostas em torno de uma ética da debilidade em outra ocasião. Não é difícil, no entanto, encontrar conexões entre estas propostas e aquelas do pós-estruturalismo francês, particularmente as de Lyotard. Lyotard não apenas faz uso da diagnose nilista de Nietzsche e, também, radicalizando-a reconhece um declínio da narrativa. Vattimo, no entanto, como Lyotard, não se aventura em perscrutar o âmbito das novas formas de racionalidade. Isto enfraquece o seu enfoque, que se limita, na maioria das vezes, a um expressivo exercício de retórica, por mais que a sua análise se aproxime mais da apreensão de certas características fenomênicas imediatas da realidade cultural da modernidade tardia. $O$ que aliás faz com muita minúcia, revelando aspectos nem sempre considerados pelos seus críticos defensores do projeto moderno. Cabe notar que na compreensão da relação da arte, da técnica e da ciência com o passado, Vattimo também se alimenta da mesma fonte dos entusiastas defensores do projeto moderno, como Tomás Maldonado e Habermas, isto é, das teorizações de Thomas Kuhn (14).

A estas considerações sumárias sobre as tendências hoje operantes e que ilustram uma evasão da utopia para o âmbito religioso, o que denota uma perda de confiança em si mesma da cultura ocidental moderna, cabe incorporar agora as críticas de Lyotard ao fenômeno da crise de legitimidade dos paradigmas da experiência moderna. É o que ele denomina de crise de legitimação dos metarrelatos - métarécit - particularmente o da emancipação. Posteriormente analisaremos os argumentos contrários de Apel e Habermas.

III

Segundo Lyotard, há uma variedade de jogos de linguagem, uma heterogeneidade de elementos, cada um veiculando consigo "valências pragmáticas sui generis". Metarrelatos como a "dialética do espírito, a hermenêutica do sentido, a emancipação do sujeito racional ou trabaIhador, o desenvolvimento da riqueza" não oferecem mais condições para se poder dizer sobre a legitimidade da variedade dos jogos de linguagem ou sobre a heterogeneidade de suas valências. A legitimidade, tanto em matéria de justiça social como dos critérios de verdade, é a da otimização das performances do sistema, através de seus critérios de eficácia. Com a falência do que Lyotard chama de metarrelatos, a legitimidade passa a constituir um problema, pois não pode mais ser obtida pelos critérios de operatividade, na medida em que estes não permitem distinguir o verdadeiro do falso. Assim como a legitimidade também não pode mais ser obtida através da discussão, pois violentaria a heterogeneidade dos jogos de linguagem, a invenção se produz sempre no interior não do consenso mas do "dissenso" (16, p. 8).

Para Lyotard, o conhecimento muda de status ao mesmo tempo em que as sociedades entram na era "pós-industrial" e as culturas na era "pós-moderna". Esta ultrapassagem começou no final da década de 50, quando a Europa terminava a sua reconstrução. Depois de passados quarenta anos, as ciências e as tecnologias ditas de ponta trouxeram para a linguagem "a fonologia e as teorias lingüísticas", "os problemas da comunicação e da cibernética", "as álgebras modernas e a informática", "os computadores e suas linguagens", "os problemas de tradução das linguagens", "a busca de compatibilidades entre linguagens-máquinas", "a telemática", "a paradoxologia", etc (16, p. 11-12). Essas novas tecnologias acarretaram também conseqüências ao nivel da investigação e da transmissão do conhecimento. No que diz respeito a sua transmissão, o conhecimento só pode ser transmitido em termos de quantidade de informações. A orientação das pesquisas, por seu lado, subordina-se à condição de tradutibilidade dos resultados em linguagem das máquinas. Tanto os produtores quanto os utilizadores do saber devem encontrar os meios de traduzir estas linguagens. Com a crescente hegemonia da informática, uma certa lógica se impõe sobre o conjunto de prescrições e também sobre os 
enunciados aceitos como conhecimento. O velho princípio de que o saber é indissociável e indispensável à formação (Bildung) do espírito, e mesmo da pessoa, "deixa de ter sentido" (16, p. 14). O saber será produzido para ser vendido, para ser valorizado em uma nova produção, deixando de ser portanto um fim em si mesmo. Com a informatização da sociedade o status do conhecimento muda: ele deixa de ser orientado com a finalidade de ser "original", "verdadeiro", passando a ser orientado por critérios de eficácia, de "capacidade discriminante".

Em um capítulo do seu livro, Lyotard retoma a teoria dos jogos de linguagem de Wittgenstein. Sobre os sujeitos dos jogos de linguagem observa que nestes as regras não são legítimas em si mesmas, mas resultantes de um contrato explícito. Uma modificação mínima de uma regra modifica a natureza do jogo. Todo enunciado deve ser considerado como um "lance". Isto significa que todo ato de fala é um ato de combate, no sentido do jogo, e que os atos de linguagem revelam uma "agonistica geral".

O sentido do lance se relaciona com o prazer da invenção que "é o que permite a evolução da linguagem" (16, p. 26). Em um contexto de decomposição dos grandes relatos em conseqüência da dissolução da lei social e com a passagem das coletividades sociais ao estado de uma massa de átomos individuais lançados no interior de um movimento browniano, os jogos de linguagem representariam o minimum de relação exigida para a reprodutibilidade social. Esta atomização do social em flexíveis redes de jogos de linguagem pode parecer bem distante de uma realidade moderna permanentemente paralisada, bloqueada por aparatos burocráticos. No uso cotidiano, em uma discussão, no entanto, elas podem encerrar uma maior flexibilidade dos enunciados. A burocratização seria o limite desta tendência (16, p. 26). Cabe observar que a utilização feita por Lyotard do conceito de jogos de linguagem do último Wittgenstein não tem como meta a explicação do funcionamento das relações de comunicação intersubjetivas no interior da própria socialidade, ao contrário, Lyotard coloca-o fora dos contextos institutionais, distante do "grande mundo", e sem qualquer possibilidade ou finalidade de mudar as regras deste. No limite, a aplicação do conceito de jogos de linguagem restringe-se ao âmbito do ócio, como uma prazerosa experiência estetizante de um diálogo engenhoso. Como observa A. Honneth, Lyotard "projeta Nietzsche em Wittgenstein" (13, p. 895).

O grande relato, seja ele especulativo ou emancipador, perdeu sua credibilidade. $O$ declínio dos relatos é resultado do avanço das técnicas e das tecnologias que ocorreu a partir da Segunda Guerra Mundial e que acentuou a importância dos meios em relação aos fins. Este processo é simultâneo à grande transformação do capitalismo liberal avançado durante os anos 1930 a 1960. Esta renovação, segundo Lyotard, "eliminou a alternativa comunista e valorizou o desfrute individual e dos serviços" (16, p. 68).

Lyotard toma o movimento cultural que vai da diagnose niilista de Nietzsche até o pessimismo estético e literário das vanguardas em Viena na virada do século como a "pré-história da pós-modernidade". Nietzsche mostrou que o niilismo europeu resultou da auto-aplicação das exigências científicas de verdade a estas próprias exigências. Este processo de deslegitimação Wittgenstein entendeu à sua maneira. A ciência faz seu próprio jogo de linguagem. Ela não pode legıtimar outros jogos de linguagem. Disto resulta uma conclusão pessimista: "ninguém pode falar todas as línguas, não há metalinguagem universal". Foi este pessimisṃo que nutriu a geração de intelectuais vienenses na virada do século: artistas como Musil, Kraus, Hofmannsthal, Loos, Schöenberg, Broch, e também filósofos como Mach e Wittgenstein (Nota E; 16, p. 68).

A crítica de Lyotard aos relatos de emancipação, e principalmente ao modelo de consenso, 
é dirigida contra a tradição do idealismo alemão, principalmente à ética da "comunidade da comunicação" defendida por K. O. Apel e J. Habermas. Lyotard expressa seu ceticismo em relação à possibilidade de $s \in$ fundar racionalmente uma ética em uma época de crise de legitimidade dos relatos de emancipação decorrente do desenvolvimento das ciências, pois para ele isto afeta diretamente a idéia da validade intersubjetiva. Mas é possivel se contentar com normas morais reguladoras da convivência humana cuja validade se restrinja aos pequenos grupos, aos acordos meramente locais, remetendo a relação entre os grupos à destrutiva luta darwinista pela sobrevivência? A situação é paradoxal: nunca a questão de se construir uma ética racional se mostrou tão sem esperanças e ao mesmo tempo tão imprescindivel, dado que a possibilidade de extermínio catastrófico da espécie não é mais uma mera mitologia terrificante, como em outros tempos, mas uma possibilidade concreta. Esta possibilidade afeta não apenas um limitado grupo de pessoas, mas o "gênero humano" como um todo. No entanto, predomina, no horizonte da modernidade tardia, a idéia generalizada e amplamente difundida - seja através dos meios de comunicação de massa ou nas discussões restritas dos círculos intelectuais de que são remotas tanto as possibilidades de uma objetividade científica no âmbito das ciências lógico-matemáticas e das ciências empírico-analíticas quanto as possibilidades de uma validade intersubjetiva dos argumentos. $E$ isto porque os juízos de valor não podem ser deduzidos nem dos formalismos das conclusões lógico-matemáticas nem das conclusões indutivas com base em fatos. A idéia da objetividade científica difere da pretensão de validade das normas e dos juízos de valor no âmbito da subjetividade não vinculante. Walter Benjamin, no aforismo "Posto de gasolina", expressou de modo profético, já na década de vinte, esta situação paradoxal hoje imperante: "A construção da vida, no momento, está muito mais no poder dos fatos que de convicções. $E$, aliás, de fatos tais, como quase nunca e em parte nenhuma se tornaram fundamento de convicções" (2, p. 5).

O conceito de "dialética" como decurso histórico objetivamente necessário está em contradição tanto com a idéia moderna da objetividade científica como também com a da livre decisão moral da consciência. Este conceito de realidade "concreta", como realidade em processo, comum a Hegel, Marx e ao tardio Whitehead, segundo Apel, "não está de fato em condições de 'eliminar' a distinção, relevante tảnto na prática como na ética, entre o que é agora e o que deve ser" (1, p. 211). Enquanto filosofia dialética o marxismo não aceita a separação entre ser e dever-ser, entre fatos cognosciveis cientificamente e normas fixadas subjetivamente. $A$ idéia de que a humanidade só se coloca tarefas para as quais pode encontrar solução e que ela tem diante de si a tarefa de "superar" a sua pré-história natural, isto é, o particularismo atomizante dos interesses de grupos e classes, representa um aspecto positivo do antagonismo entre o que é e o que deve ser. Ser e dever-ser, fatos do conhecimento e normas subjetivas, no que diz respeito a sua função ideológica, na verdade não se contradizem, mas se complementam.

Segundo Apel, há uma conexão, uma "complementaridade oficial", entre "misticismo" e "subjetivismo existencial", entre "solipsismo transcendental" (Wittgenstein) e "comunicação indireta" (Kierkegaard) ou "iluminação da existência" (Jaspers). Para Apel, "a complementaridade entre objetivismo avalorativo das ciências, de um lado, e subjetivismo existencial dos atos de fé religiosos e das decisões éticas, de outro, são a moderna expressão filosófico-ideológica da separação liberal entre âmbito público e âmbito privado da vida" (1, p. 214). Isto tem como conseqüência geral que em praticamente todos os âmbitos da vida pública os fundamentos morais da práxis são substituídos por argumentos pragmáticos que podem ser fornecidos pelos especialistas com base em regras científico-tecnológic as objetiváveis. Apel lembra que Weber descreveu a racionalidade da esfera pública, do comércio e da administração burocrática do estado como um processo indissociável. Esta análise e este processo se ampliaram e se ge- 
neralizaram principalmente com o auxilio da cibernética e com a teoria funcionalista da sociedade como sistema. Nos dias atuais o "pragmatismo instrumentalista" se tornou parte componente da filosofia analítica e do pensamento publicamente ativo. Isto se efetivou não sem acarretar problemas teóricos insolúveis, como, por exemplo, os das dificuldades metodológicas da "ordinary language philosophy" em geral. Já no último Wittgenstein estes aparecem fundados no fato de ele não refletir sobre a relação "comunicativo-reflexiva" entre os "jogos de linguagem" e as "formas de vida" por ele descritos, que permanecem entre uma "análise transcendental" e uma "análise quase behaviorista" (1, p. 226).

O que escapa à análise de Lyotard é que as flexiveis redes dos jogos de linguagem plurais são inimagináveis sem pressupor o que Apel chama de uma comunidade da comunicação de indivíduos capazes de ilimitada comunicação e de consensos intersubjetivos. Mesmo o pensador solitário só pode explicar e controlar a sua argumentação enquanto está em condições, no "colóquio da alma consigo mesma" (Platão), de interiorizar o diálogo de uma comunidade da argumentação racional. Isto significa que não se pode seguir uma regra sozinho. Mesmo no âmbito privado, a linguagem, para ser reconhecida como válida, é em princípio pública. Compreender a si mesmo e ao outro significa conceber as condições de possibilidade e de validade da compreensão do sentido. Para Apel, a afirmação de Wittgenstein, contida nas Investigações filosóficas, de que "não é possível que um só homem tenha seguido uma regra uma só vez", parte do pressuposto do jogo lingüístico como condição dos critérios de prova e portanto da validade das "regras" e da "observância de regras" (1, p. 238). Em uma observação marginal, Apel destaca que Wittgenstein nada tem a ver com o behaviorismo, porque este substitui a compreensão da ação, que decorre da comunicação, pela observação meramente exterior do comportamento (1, p. 238-239).

O sentido da comunidade da comunicação tem como pressuposto o reconhecimento de todos os membros com iguais direitos de discussão. Deste ponto de vista, na dimensão pragmática do discurso, a "competência comunicativa" (Habermas) é primária em relação à "competência gramatical" (Chomsky) (1, p. 239). A tese desenvolvida por Habermas da possibilidade de se poder, em princípio, verbalizar todas as ações e todos os gestos expressivos é sugerida pela descoberta de Austin da "manifestação executiva" e da sua generalização e radicalização na história dos "atos lingüísticos" de J. R. Searle (1, p. 239). Essa comunidade da comunicação se apresenta portanto como possibilidade de comunicação de sentido e de justificação dialógica para as operações monológicas das ciências.

A comunidade da comunicação como a priori, conforme os argumentos de Apel, não significaria um retroceder à concepção idealista da "dialética do espírito". Esta comunidade não tem como pressuposto o a priori da "consciência". Ela significa, segundo Apel, "uma comunidade real da comunicação, e quem argumenta se torna ele mesmo membro através do processo de socialização e, em segundo lugar, uma comunidade ideal da comunicação que esteja em condições de em princípio compreender adequadamente os sentidos dos seus argumentos e de julgar definitivamente a sua verdade. O elemento singular e dialético desta situação está portanto em que ele de certo modo pressupõe a comunidade ideal na comunidade real, isto é, como possibilidade real da sociedade real, mesmo que ele saiba que na maior parte dos casos "a comunidade real... está longe de assemelhar-se à comunidade ideal da comunicação" (1, p. 263). Uma contradição no sentido não metafórico que, como tal, deve "ser suportada" (Hegel), e que só pode encontrar uma verdadeira "superação" através da realização da comunidade ideal da comunicação no interior da comunidade real da comunicação. Esta exigência implica que toda argumentação possa ser derivada de dois princípios regulativos fundamentais para a estratégia moral das ações de cada homem; todo agir deve garantir a sobrevivência do gênero

Trans/Form/Ação, São Paulo, 11: 31-44, 1988. 
humano como sobrevivência da comunidade real da comunicação e ter como questão a realização da comunidade ideal no interior da comunidade real.

A argumentação habermasiana se aproxima, em princípio, do programa da ética do discurso de Apel: ambos têm como meta a realização da comunidade ideal da comunicação na comunidade real. Deixando de lado as diferenças existentes entre os dois filósofos, convém esclarecer como Habermas chega à realização da "guinada lingüística" que sustenta a sua teoria crítica "positiva", isto é, a sua teoria do agir comunicativo. Nos limitaremos a descrever a sua crítica ao materialismo histórico e, posteriormente, a sua análise da relação entre racionalização e reificação no marxismo ocidental desenvolvida por Lukács e Adorno.

1. Já no livro Conhecimento e Interesse (1968) Habermas tentou demonstrar que conceitos holísticos como atividade produtiva e práxis requerem a decomposição em conceitos fundamentais do agir comunicativo e do agir racional-teleológico, e isto mais precisamente para evitar uma associação arbitrária, uma mistura de dois processos de racionalização. As ações racional-teleológicas podem ser examinadas tanto sob o aspecto da virtualidade empírica dos meios técnicos como sob o aspecto da consistência da escolha entre meios adequados. Em ambas as dimensões é possivel racionalizar as ações e os sistemas de ação. Habermas denomina de ação estratégica aquela em que existem atores contrapostos que buscam exercer mútua influência. Ele chama a atenção para o fato de que Marx viu a racionalização dos meios e a eleição dos próprios meios, nos contextos de ação social, como um incremento das forças produtivas. Nelas Marx distingue: as estruturas de racionalidade, o processo de aprendizagem e as condições marginais para implementar saberes disponiveis e capazes de repercussão social. Somente nestes três conjuntos de complexos de condições é possível explicar os processos de racionalização, no sentido marxiano, de desenvolvimento das forças produtivas. Mas ele insiste que há outros processos de racionalização com igual importância para a explicação da evolução social. Aí está a base, para Habermas, da confusão ou do nexo não esclarecido entre progresso técnico-organizacional, de um lado, e luta de classes, por outro (10, $p$. 32-33).

A diferença entre agir racional-teleológico e agir comunicativo está, entre outros aspectos, no acatamento de normas de validade intersubjetivas que conectam expectativas reciprocas de comportamento e que se validam pelo discurso. As pretensões de validade - segundo Habermas - "tornam possivel o consenso que serve de base comum ao agir" (10, p. 33). SemeIhante consenso falta ao agir estratégico: "nele não se espera a veracidade das intenções observadas, e a conformidade de um acerto com as normas... é pressuposta em um sentido distinto daquele que se apresenta concretamente no caso do agir comunicativo na forma contingente. Alguém que jogando xadrez repete mais de uma vez movimentos sem sentido, desqualifica-se como jogador de xadrez; e quem segue outras regras distintas àquelas que configuram o jogo, este não está jogando precisamente xadrez. Enquanto a ação estratégíca permanece indiferente às suas condições motivacionais, os pressupostos consensuais do agir comunicativo podem assegurar as motivações" (10, p. 33). A institucionalização das normas de validade intersubjetivas do agir estratégico permite assegurar o cumprimento das condições motivacionais. Esta institucionalização permite "separar o aspecto do agir racional-teleológico, ou dito em termos parsonianos, o 'aspecto funcional', do marco do agir comunicativo" (10, p. 33).

O que se pressupõe no caso do agir racional-teleologico é simplesmente que todos os sujeitos atuantes sigam preferências e máximas decisórias determinadas (em monólogo) para si 
mesmos. O agir comunicativo não pode ser racionalizado sob o aspecto técnico, mas somente a partir da perspectiva moral prática, da capacidade de o sujeito da ação de imputar normas e de justificá-las pelo diálogo.

A racionalização do agir comunicativo, para Habermas, consiste na reconstrução do discurso mutilado, despotenciando nele as relações de violência que se acomodam inadvertidamente nas estruturas comunicacionais e que, valendo-se de barreiras tanto intrapsíquicas como interpessoais, impedem que os conflitos sejam dirimidos e regulados conscientemente de modo consensual (10, p. 33). A racionalização aqui significa então a superação de comunicações similares sistematicamente distorcidas. As estruturas de racionalidade não se encarnam apenas nos amplificadores do agir racional-teleológico (tecnologias, estratégias, organização, etc) mas também nas mediações do agir comunicativo, nos mecanismos de controle dos conflitos, nas imagens de mundo, nas formações de identidade.

O que Marx distingue como duas dimensões, isto é, a dimensão de um processo cumulativo de desenvolvimento tecnológico (forças produtivas, no processo de trabalho) e a dimensão de um desenvolvimento de formas de domínio, de lutas de classe e de processos de emancipação (relações de produção), só é admissivel, para Habermas, sob a condição de se tirar dela todas as implicações gnoseológicas reformuladas em um outro nivel: pela distinção entre agir racional-teleológico (instrumental) e agir comunicativo. A emancipação como processo de racionalização dos conteúdos simbólicos pelo agir comunicativo se encontra, portanto, em um outro nível, fora das relações imediatamente orientadas pela racionalidade instrumental.

A decomposição antinômica do paradigma da produção em modelos do trabalho "científico" e da noção "filosófica" da práxis tem se reproduzido ao longo da história das interpretações de Marx. Para Wellmer, em consonância com Habermas, o próprio Marx não conseguiu evitar um certo relativismo histórico: a identificação entre evolução técnica e progresso social à maneira positivista. Como observa Wellmer, há um "resto positivista" na teoria de Marx, na medida em que reduz o agir comunicativo ao agir instrumental e interpreta a autoconstituição da humanidade unilateralmente do ponto de vista do trabalho como atividade técnico-racional-teleológica (21).

Com a teoria do agir comunicativo, Habermas quer chegar à análise das precondições transcendentais de uma comunicação e de um entendimento possivel, que revele as normas fundamentais para todos aqueles que querem ser considerados como seres humanos racionais (capazes de comunicar e construir um argumento) e que podem ser reconhecidas e utilizadas como justificação à perspectiva prático-ideal implícita em uma teoria crítica da sociedade capitalista contemporânea. Para György Markus, Habermas, "ao interpretar o paradigma marxiano da produção em termos de trabalho, enquanto atividade puramente instrumental e racional-teleológica, opera ele mesmo uma redução tecnicista que não se pode atribuir a Marx" (18, p. 53). Para Markus, o paradigma marxiano da produção repousa sobre uma concepção do trabalho como unidade do processo de interação entre homem e natureza e aquele entre homem e homem. A crítica de Habermas radica em um mal-entendido filosófico: reduz o conceito de desenvolvimento histórico à mera dimensão de crescimento do controle técnico sobre a natureza.

Habermas, desde o início, percebeu algo equivocado na prioridade que Marx atribuiu às forças produtivas. A tentativa de resposta sobre o que havia de equivocado foi reformulada várias vezes e de várias maneiras. $O$ contra-argumento começou a tomar forma definida em Ciência e técnica como ideologia (1968) e principalmente no livro Para a reconstrução do materialismo histórico (1976). Na Teoria do agir comunicativo Habermas demonstra que esta "redução" da 
racionalidade social à razão instrumental se encontra também na identidade entre racionalidade social e reificação feita por Lukács em História e consciência de classe.

2. A incorporação pelo "marxismo ocidental" dá teoria weberiana da racionalização foi um esforço para encontrar conexões entre a dialética (de Hegel e de Marx) do trabalho morto e do trabalho vivo e entre sistema e eticidade. Marx indaga como o processo de acumulação esvazia o mundo da vida daqueles produtores que podem oferecer como única mercadoria apenas a sua própria força de trabalho. Ele segue o processo contraditório de racionalização social luz dos movimentos autodestrutivos de um sistema econômico que se assenta no trabalho assalariado e que organiza a produção de bens como produção de valores de troca e através dessa intervenção provoca os efeitos de desagregação nas condições de vida das classes que participam de tais transações. Nesta tradição do marxismo ocidental encontram-se pois estes dois problemas decisivos para uma teoria da sociedade, fim último também da empresa habermasiana. Para Habermas trata-se de ampliar o conceito de ação teleológica desta tradição e de relativizar a atividade finalizada com o modelo do entendimento, o que pressupõe não apenas a transição da filosofia da consciência à filosofia da linguagem, mas também o desenvolvimento de uma teoria da comunicação e de uma radicalização da análise da linguagem.

Com a tese segundo a qual "na estrutura das relações de mercado pode ser encontrado o arquétipo de todas as formas de objetivação e de todas as formas correspondentes de subjetividade na sociedade burguesa", Lukács determina, segundo Habermas, "a forma de objetivação dominante na sociedade capitalista que prejudica as referências de mundo, o modo em que os sujeitos capazes de linguagem e de ação podem referir-se a qualquer coisa no mundo objetivo, no mundo social e no seu mundo subjetivo" (11, p. 474). É o que Lukács denomina de reificação. Ao conceber a racionalização e a reificação como dois aspectos de um mesmo processo, Lukács apóia-se precisamente na tese weberiana da racionalidade formal. Mas, segundo Lukács, Weber desconhece o nexo causal, pois separa "os fenômenos da reificação do fundamento econômico da sua existência e os eterniza caracterizando-os como tipos atemporais de relações humanas possiveis em geral" (11, p. 476). Como demonstra Habermas, Lukács serve-se também de outras fontes para seu conceito de racionalidade formal: a forma da mercadoria; a crítica do conhecimento intelectivo de Kant; e ainda: "ele recebe de Hegel o conceito de totalidade de um nexo vital organizado racionalmente e o usa como critério para a irracionalidade da racionalização social" (11, p. 476).

Para Habermas, as posições teóricas de Horkheimer e Adorno, dos anos 40, reforçaram as convergências entre a tese weberiana sobre a racionalização e a crítica da razão instrumental, que se situa na linha da tradição Marx-Lukács. Tanto para Horkheimer como para Weber a racionalidade formal é a base da atual cultura industrial: a eficácia dos meios disponiveis sob o aspecto instrumental e a justeza na escolha dos meios sob o aspecto estratégico. Horkheimer sublima particularmente a perda de racionalidade que se verifica na medida em que ações podem ser racionalizadas, planificadas e justificadas apenas nos aspectos cognoscitivos. Horkheimer apóia-se também na interpretação de Lukács da racionalização capitalista como reificação. Ele introduz a razão instrumental como "razão subjetiva" contrapondo-a à "razão objetiva". "No centro da teoria da razão objetiva - segundo Horkheimer - não estavam correlações entre comportamento e fim, mas os conceitos - por mais mitológicos que possam parecer hoje - se ocupam da idéia do bem supremo, do problema da destinação (Bestimmung) humana e como são realizáveis os fins supremos". "Os sistemas filosóficos da razão objetiva implicavam o convencimento de que se poderia descobrir uma estrutura onicompreensiva ou fundamental do ser e que dela se poderia derivar uma concepção de destinação (Bestimmung) humana (11, p.463). Horkheimer, segundo Habermas, vê a esfera dos valores normativos e expressivos 
como privada de qualquer instância de validade imanente, de modo que não se pode mais falar de racionalidade moral e estética, mas, em contrapartida, toma o pensamento especulativo, transformado em crítica, como ainda capaz de força restitutiva - o que Weber teria considerado como utópico. Mas ambos concordam com a tese segundo a qual "desagrega-se a unidade fundadora de sentido das imagens metafísico-religiosas" (o processo de desencantamento, como processo de racionalização, CEJM) - e que tal circunstância coloca em discussão a unidade dos mundos da vida modernizados, comprometendo assim seriamente a identidade dos sujeitos socializados e a sua específica solidariedade social" (11, p. 467).

Enquanto a tese sobre a perda de sentido é derivada do processo de racionalização cultural, a tese sobre a perda da liberdade é derivada do processo de racionalização social. Mas enquanto em Weber a diagnose passa diretamente a considerações terapêuticas, Adorno e Horkheimer se interessam pelo significado que assume a autonomização dos subsistemas do agir racional-teleológico - que corresponde a "auto-alienação dos indivíduos, que devem modelar-se, corpo e alma, segundo as exigências do aparato técnico" (11, p. 473). Horkheimer e Adorno chamam a atenção para o nexo que a racionalização social parece estabelecer entre a transformação dos âmbitos tradicionais de vida em subsistemas do agir racional teleológico, de um lado, e a atrofia (Nota F) da individualidade, de outro (11, p. 473).

Na Dialética do lluminismo Adorno e Horkheimer contestam a proposição lukacsiana segundo a qual a racionalização aparentemente integral do mundo encontra seus limites no caráter formal da própria racionalidade. Eles demonstram no plano empírico a existência de um processo selvagem de reificação da cultura e da natureza interior, e no plano teórico, que o idealismo objetivo, prolongado em sentido hegeliano-marxista, reproduz em si mesmo a estrutura da consciência reificada. Com isso, eles radicalizam a crítica lukacsiana da reificação. Em contrapartida às ciências, Adorno resgata o poder da filosofia das origens, "uma razão anterior à razão". O lugar desta razão originária ele o encontra na faculdade mimética. Ela poderia fazer falar o que a natureza instrumentalizada mitiga como lamento mudo.

Para Habermas: "o paradoxo em que se enreda a crítica da razão instrumental e que se opõe obstinadamente também à dialética mais flexível é dado principalmente pelo fato de que Horkheimer e Adorno deveriam formular uma teoria da mímese, impossivel em base aos seus próprios conceitos. Por isso é coerente que eles não tenham tentado explicar a 'reconciliação' universal (Universale Versöhnung), como ainda tentou Hegel, enquanto a unidade da identidade e da não-identidade do espírito e da natureza, e por isso mesmo deixam que permaneçam como uma cifra, quase em termos de filosofia da vida" (11, p. 513). Esta idéia pode ser encontrada tanto nas imagens da mística judaico-cristã como na fórmula do jovem Marx do nexo dialético entre humanização da natureza e naturalização do mundo humano. Ela constitui o motivo comum da reflexão tanto de Adorno e Horkheimer como da do jovem Lukács, de Bloch e Benjamin e da "filosofia da práxis".

Adorno e Horkheimer se deixam orientar pela idéia da reconciliação, mas renunciam ao mesmo tempo a explicitá-la e a fazer dela uma metafísica. Isto conduz, segundo Habermas, às aporias de uma crítica que reduz, em certo sentido, a pretensão do conhecimento teórico: "a crítica da razão instrumental, que é conceitualizada na Dialética negativa, operando com os meios da teoria, contradiz a sua própria pretensão teórica" (11, p. 518). E acrescenta: "A crítica da razão instrumental, que permanece ligada aos condicionantes da filosofia do sujeito, denuncia como defeito aquilo que ela, na sua defeituosidade, não está em condições de explicar porque lhe falta uma conceitualização suficientemente flexível para a integridade daquilo que é destruído pela razão instrumental". Ao final de sua análise, Habermas lembra que "na sua Estética Adorno se esforça em mostrar que a obra de arte deve sua força reveladora à mímese. 
Mas no trabalho (Leistung) mimético o núcleo racional pode se manifestar apenas quando se abandona o paradigma da filosofia da consciência. O paradigma de um sujeito que representa os objetos e se atormenta com eles dá lugar ao paradigma da filosofia da linguagem, do entendimento intersubjetivo ou da comunicação e insere a dimensão parcial cognoscitiva-instrumental em uma racionalidade comunicativa mais ampla" (11, p. 523).

O paciente trabalho de Habermas sobre o tema da emancipação como antagônica à racionalização, seu esforço de reconstruir através do agir comunicativo aquele tecido que a racionalização desfia é - como observou Remo Bodei - a "apologia de uma razão débil mas mais humana contraposta a uma razão potente mas desumanizante" (3). Em Habermas, segundo Bodei, "resiste ainda em forma atenuada o ideal dialético adorniano de uma subjetividade militante capaz de resistir à violência e às adulações do existente, que sabe dizer 'não', que quer defender a sua 'não identidade', a sua especificidade contra os mecanismos de massificação do 'mundo administrado"' (3).

Na ótica de Bodei, a forma de invalidar o ideal de criar uma comunidade da comunicação ilimitada na sociedade, contido nas estratégias teóricas de Apel e de Habermas, é reconhecê-lo também como um mero efeito do poder. Para Foucault, seria ingênuo manter o sujeito isento na sua interioridade das manipulações do poder. Como observa Bodei, a importância dos resultados de Foucault está no fato de que eles alertam para "os mecanismos e os processos de construção da individualidade, mostram como a ênfase colocada precedentemente sobre a continuidade e a identidade do eu se apóiam sobre o esquecimento e pelo apagamento das operações realizadas para a estruturação do sujeito" (3). Estes resultados teóricos de Foucault decorrem do impasse, da crise da reprodução relativamente ordenada das individualidades sociais; da descoberta de que elas são "produtos artificiais, como a natureza do singular é intimamente uma segunda natureza governada por técnicas construtivas anônimas" (Nota G; 12; 8).

\section{NOTAS}

A - É impossível condensar aqui os argumentos relevantes sobre a recepção ainda tímida entre nós da teoria do agir comunicativo e do novo paradigma de racionalidade em Habermas. Não se pode esquecer, entretanto, a crítica de Giannotti à separação efetuada por Habermas entre trabalho (agir racional-teleológico) e razão comunicativa. Ver também mais adiante, na parte $\mathrm{V}$, os comentários em chave antropológica do exassistente de G. Lukács, G. Markus. Vale lembrar igualmente as palavras intrigantes de Lebrun: "O que acho interessante em Habermas é que ele é talvez o primeiro filósofo que teve a coragem de construir um sistema neokantiano hoje em dia. Isto comporta sérios riscos, dos quais acho que Habermas não escapou totalmente: um certo enciclopedismo" (15).

B - A expressão é de Tomás Maldonado: "É difícil imaginar que o narcisismo lingüístico-literário hoje em moda constitua uma base real para se poder continuar a pensar" (17, p. 2).

C - Empregamos a expressão "Nachbücher" (conhecimento livresco) de Cacciari contra ele mesmo. Mas não se pode deixar de considerar sua crítica incisiva contra os movimentos pós-vanguardistas tanto pelo seu reducionismo como pela sua incapacidade de conhecer a "luz incerta do cotidiano", "talvez o terreno hoje mais atual de nosso mundo político deperecido" (5).

D - Esquematicamente, a "pós-história" indica a condição em que o progresso - um dos paradigmas-chave da moderna consciência do tempo - torna-se rotina. O progresso sofreu uma secularização, perdeu seu poder de atração, de influir na vida dos homens. O termo "pós-história" foi empregado pela primeira vez por Arnold Gehlen no ensaio "Die Sekularizierung des Fortschritts" (1967). É como se tivéssemos chegado - segundo a crítica de Lukács a Gehlen, num ensaio do mesmo ano - "a um paraíso do consumo integral, dotado de todos os truques refinados da manipulação das almas, ao fim da história".

Trans/Form/Ação, São Paulo, 11: 31-44, 1988. 
E - É sintomático que Lyotard ao analisar a cultura vienense deste período não leve em consideração a experiência de organização e de linguagem das formas políticas de racionalização social implementados pela social-democracia austríaca na "Viena Vermelha", experiência esta orientada pela "idéia reguladora" de uma terza via entre a social-democracia alemã e o bolchevismo soviético. Mesmo hoje esta experiência continua a exercer uma atração considerável. Não é por acaso que seu livro, apesar do número exaustivo de referências, não menciona as obras de Magris, Marramao e Schorske, publicados na década de setenta ou antes.

F - O que Adorno chama de Regressionssehnsucht (desejo de regressão) é um fenómeno eminentemente moderno, reação diante do progressivo processo de racionalização. Peter Bürger efetua uma crítica não-dogmática a esta tese adorniana (4).

G - A crítica de Habermas a Foucault estava certamente influenciada pela recepção alemã do pós-estruturalismo francês (12). Constata-se que seus argumentos se apóiam em boa medida nos trabalhos de Axel Honneth sobre Foucault e de Manfred Frank sobre o pós-estruturalismo (8). Há uma certa expectativa sobre a releitura de Sartre proposta por Habermas, que mais recentemente se tem revelado um ensaísta briIhante. Por mais que sua preocupação não esteja ligada à problemática estético-estilística, como nos jovens Lukács, Bloch, Benjamin e Adorno, esta nova fase ensaística tem possibilitado a manifestação de uma polifonia de vozes em sua teoria da sociedade - o que em geral também é estranho ao mutismo das teorias sistêmicas.

MACHADO, C. E. J. - The concept of rationality in Habermas: The linguistic turn of the critical theory". Trans/Form/Ação, São Paulo, 11: 31-44, 1988.

ABSTRACT: This essay was a speech pronounced in UNICAMP. It was written for Habermas' brasilian visiting expected at the second semester of the past year. Its unmediate goal was to give some informations about the last Habermas' reflections. Therefore, it tried to insert Habermas'proposal of a "communicative reason" in our days with the generalized irruption of fragmentaries, relativistic and irrationalistic discursive forms (the French "poststruturalism" and the Italian "pensiero debole" are the analysed examples). Without claiming to exhaust a so complex subjet, it also tried to put some questions about the critical-cognitive possibilities of the linguistic turn of Habermas' and Apel's philosophy.

KEY-WORDS: Reason x irrationalism; opacity; "weak thought"; posthistory; poststructuralism; community of communication; the rational-teleological action x communicative action; critic of critical theory.

\section{REFERÊNCIAS BIBLIOGRÁFICAS}

1. APEL, K. O. - Communità e comunicazione. Torino, Rosenberg, 1977.

2. BENJAMIN, W. - Strada a senso unico. Torino, Einaudi, 1983.

3. BODEI, R. - Stratagie di individuzzione. Aut-Aut, mar./giug., 1985. Trad. do Autor. Presença, n 9, 1986.

4. BÜRGER, P. - Der Alterns der Moderne. In: ADORNO, T. - Konferenz. Frankfurt, Suhrkamp, 1983.

5. CACCIARI, M. - Depoimento. In: OLIVA, B. - Avanguardia Transvanguardia. Milano, Electra, 1982.

6. CACCIARI, M. - Dello Steinhof. Milano, Adelphi, 1980.

7. CACCIARI, M. - Icone della legge. Milano, Adelphi, 1985.

8. FRANK, M. - Was heisst Neostrukturalismus? Frankfurt, Suhrkamp, 1984.

9. HABERMAS, J. - A nova intransparência. Trad. Carlos Alberto M. Novaes. Novos Estudos, n $18,1987$.

10. HABERMAS, J. - La reconstrucción del materialismo histórico. Madrid, Taurus, 1981.

11. HABERMAS, J. - Theorie des kommunikativen Handelns. Frankfurt, Suhrkamp, 1981. vol. I.

Trans/Form/Ação, São Paulo, 11: 31-44, 1988. 
12. HABERMAS, J. - Der philosophische Diskurs der Moderne. Frankfurt, Suhrkamp, 1985.

13. HONNETH, A. - Der Affekt gegen der Allgemein. Merkur., 12, 1984.

14. KUHN, T. - Comment on the relations of science and art. In: - The essential tension. Chicago, Univ. of Chicago Press, 1977.

15. LeBRUN, G. - Depoimento a Marco Chiaretti. Folha de São Paulo, São Paulo, 02/08/1987.

16. LYOTARD, J. F. - La Condition postmoderne. Paris, Minuit, 1979.

17. MALDONADO, T. - Il futuro della modernità. Milano, Feltrinelli, 1987.

18. MARKUS, G. - Die Welt menschlicher Objekte. In: HONNETH, A., org. - Arbeit, Haudlung, Normativität. Frankfurt, Suhrkamp, 1980.

19. ROVATTI, P. A. \& VATTIMO, G. - II pensiero debole. Milano, Feltrinelli, 1983.

20. VATTIMO, G. - La fine della modernità. Milano, Feltrinelli, 1985.

21. WELLMER, A. - Comunicacione e emancipazione. Dialectica della racionalizazione. Milano, Unicopoli, 1983. 